\title{
Reliability of a computational model for evaluating thoracoabdominal mobility in newborns: a cross- sectional study
}

\section{Danielle Cristina Gomes}

Universidade Federal do Rio Grande do Norte

Ingrid Guerra Azevedo ( $\square$ iguerra@uct.cl)

Universidad Católica de Temuco https://orcid.org/0000-0001-7305-7583

Ana Gabriela Figueiredo Araújo

Universidade Federal do Rio Grande do Norte

Norrara Scarlytt de Oliveira Holanda

Universidade Federal do Rio Grande do Norte

\section{Fabrício Anicio Magalhães}

Universidade Federal de Minas Gerais

\section{Silvana Alves Pereira}

Universidade Federal do Rio Grande do Norte

\section{Research}

Keywords: Respiratory Mechanics, Photogrammetry, Infant, Newborn, Video Recording

Posted Date: August 31st, 2020

DOl: https://doi.org/10.21203/rs.3.rs-63454/v1

License: (9) (i) This work is licensed under a Creative Commons Attribution 4.0 International License. Read Full License 


\section{Abstract}

Background: Thoracoabdominal mobility (TAM) in newborns (NB) is an important respiratory function parameter in clinical assessment. Different systems have been proposed to assess compartmental mobility in a number of pathologies and age ranges. The present study aimed to verify the inter and intraexaminer reliability of an interactive custom-made MATLAB $\AA$ App for bio-photogrammetric analysis of thoracoabdominal mobility in newborns (NB) and compare the respiratory rate (RR) results between the automatic MATLAB® App and its manual counterpart.

Methods: This is a cross-sectional study conducted in 27 healthy NB of both sexes (gestational age between 37 and 41 weeks and up to 72 hours of life) who did not cry during data acquisition. Chest and abdominal areas of the NB in the supine position were analyzed through 60 s videos, totaling 30,714 photograms. All photograms were analyzed by three examiners on three different occasions. Analysis of variance (ANOVA) and intraclass correlation coefficient (ICC) were applied, adopting a 95\% confidence interval and significance level of $a=0.05$.

Results: Reliability was excellent for intra (ICC 0.81 - 0.96) and inter-examiner correlations (ICC 0.840.99 ) between the chest and abdominal areas, in both inspiration and expiration, with no differences between them.

Conclusions: Evaluation of NB thoracoabdominal mobility using the custom-made MATLAB® App for bio-photogrammetric analysis exhibited good to excellent intra- and inter-examiner reliability and an excellent correlation between manual and automatic models for measuring RR. Thus, it proved to be an objective and practical tool for bedside thoracoabdominal mobility assessment in different clinical situations involving neonatal care.

\section{Background}

Thoracoabdominal mobility (TAM) in newborns (NB) is an important respiratory function parameter in clinical assessment, since it is closely related to alveolar ventilation, inspiratory muscle strength and pulmonary capacity [1-3]. TAM in NB involves the contribution of thoracic and abdominal compartments to respiratory pattern, and how they relate to one another during breathing [1-4].

Different systems have been proposed to assess compartmental mobility in a number of pathologies and age ranges $[1,5-9]$. Some currently available methods have been designed to evaluate lung volume, capacities, limitations and breathing patterns in NB in an efficient and non-invasive manner, such as optoelectronic plethysmography (OEP) $[9,10]$, inductive respiratory plethysmography (IRP) [11] and electrical impedance tomography (EIT) [12]. However, these are mostly restricted to laboratory environments, require technical personnel, are time-consuming and not user-friendly, limiting their use in clinical practice. 
Although OEP is capable of measuring subdivisions between the expansion of the right and left hemithorax, the instrument is quite costly [13]. IRP detects changes in thoracic and abdominal volume during inspiration/expiration and, when properly calibrated, the sum of the two signals can provide an estimate of tidal volume [14]. However, calibration may be difficult to maintain for a prolonged period. EIT devices, in turn, generate up to 50 images per second, which allows the dynamic study of ventilation distribution and regional lung perfusion. Nevertheless, there is a need for more clinical validation studies to explore the full potential of the technology, especially in NB [15].

On the other hand, bio-photogrammetry has been described as a more accessible and usable method for analyzing thoracoabdominal compartment mobility and synchrony in clinical practice $[6,7,16-18]$. It makes it possible to record the variation in geometric delimitation of body compartments and capture the kinematics through a set of photograms $[6,7,17,18]$. Although there is specific software for this type of analysis, such as SAPO ${ }^{\circ}$ (SAPO $\vee 0.68 \AA$, Santa Maria, Brazil), its application is focused on postural analysis [19] or general movement analysis.

Two software programs have been developed using AutoCAD $\AA$ in the respiratory pattern analysis of NB $[6,16]$ and $\operatorname{MATLAB} \AA[7,20]$, but they were not initially designed for kinematic analysis in the hospital environment. Thus, in order to be more relevant to health professionals, the present study aimed to verify the inter- and intra-examiner reliability of an interactive custom-made MATLAB® App for the biophotogrammetric analysis of TAM in NB. As secondary objectives, we aimed to compare the respiratory rate $(\mathrm{RR})$ results between the automatic MATLAB® App and its manual counterpart.

\section{Results}

A total of 50,571 photograms were collected, but 19,857 were excluded for not meeting the inclusion criteria, thereby leaving 30,714 photograms eligible for analyses. Most of the participants were boys (72.2\%) born vaginally (55.6\%). The NB exhibited an average RR of $54 \pm 11$ breaths per minute, and $29 \mathrm{~h}$ \pm 19 hours of life when evaluated. Table 1 shows chest and abdominal mobility during inspiration and expiration. The results show excellent reliability for all the areas between assessments 1,2 and 3 , since all ICC values were between 0.81 and 0.96 ( $p<0.001)$, with no statistically significant difference between the measures obtained in the three evaluations when compared using ANOVA (Table 2). Additionally, inter-examiner reliability of the measures was considered excellent for all the areas assessed by examiners 1, 2 and 3 (ICC between 0.84 and 0.99). Table 3 shows good correlation between manual and automatic methods for measuring RR, with all $r$ values $>0.95$, with $p<0.001$ (Table 3 ). 
Table 1

Average values of the thoracoabdominal areas evaluated.

\begin{tabular}{|lcccccc|}
\hline & \multicolumn{2}{c}{ Examiner 1 } & \multicolumn{2}{c|}{ Examiner 2 } & \multicolumn{2}{c|}{ Examiner 3 } \\
\cline { 2 - 7 } & Mean & SD & Mean & SD & Mean & SD \\
\hline Chest area $\left(\mathbf{c m}^{2}\right)$ & & & & & & \\
\hline Expiration & 55.6 & 8.4 & 53.8 & 8.8 & 56.6 & 8.8 \\
\hline Inspiration & 56.2 & 8.5 & 58.1 & 9.6 & 57.1 & 8.9 \\
Abdominal area $\left(\mathrm{cm}^{2}\right)$ & & & & & & \\
\hline Expiration & 88.4 & 18.6 & 83.4 & 17.4 & 90.2 & 18.3 \\
\hline Inspiration & 89.9 & 18.6 & 90.1 & 19.1 & 91.7 & 18.2 \\
\hline $\mathrm{cm}^{2}$ : square centimeters; SD: Standard Deviation. & & & \\
\hline
\end{tabular}


Table 2

Analysis of variance and intra and inter-examiner reliability for the thoracoabdominal mobility assessment of newborns using the MATLAB® App.

\begin{tabular}{|c|c|c|c|c|c|c|c|c|c|}
\hline & \multicolumn{3}{|c|}{ 1st Assessment } & \multicolumn{3}{|c|}{ 2nd Assessment } & \multicolumn{3}{|c|}{ 3rd Assessment } \\
\hline & $p$ & $I C C$ & $95 \% \mathrm{Cl}$ & $p$ & $I C C$ & $95 \% \mathrm{Cl}$ & $p$ & ICC & $95 \% \mathrm{Cl}$ \\
\hline \multicolumn{10}{|c|}{ Intra-examiner } \\
\hline \multicolumn{10}{|l|}{ chest area } \\
\hline Expiration & 0.389 & $0.96^{\star}$ & $\begin{array}{l}0.92- \\
0.98\end{array}$ & 0.717 & $0.94^{\star}$ & $\begin{array}{l}0.88- \\
0.98\end{array}$ & 0.751 & $0.95^{\star}$ & $\begin{array}{l}0.90- \\
0.98\end{array}$ \\
\hline Inspiration & 0.972 & $0.95^{\star}$ & $\begin{array}{l}0.91- \\
0.98\end{array}$ & 0.914 & $0.91 *$ & $\begin{array}{l}0.81- \\
0.96\end{array}$ & 0.409 & $0.81 *$ & $\begin{array}{l}0.63- \\
0.91\end{array}$ \\
\hline \multicolumn{10}{|c|}{ Abdominal area } \\
\hline Expiration & 0.455 & $0.94^{\star}$ & $\begin{array}{l}0.87- \\
0.97\end{array}$ & 0.572 & $0.92 *$ & $\begin{array}{l}0.83- \\
0.96\end{array}$ & 0.552 & $0.94^{\star}$ & $\begin{array}{l}0.87- \\
0.97\end{array}$ \\
\hline Inspiration & 0.934 & $0.94^{*}$ & $\begin{array}{l}0.86- \\
0.97\end{array}$ & 0.939 & $0.91 *$ & $\begin{array}{l}0.82- \\
0.96\end{array}$ & 0.940 & $0.92^{\star}$ & $\begin{array}{l}0.84- \\
0.97\end{array}$ \\
\hline \multicolumn{10}{|c|}{$\begin{array}{l}\text { Inter-examiner } \\
\text { chest area }\end{array}$} \\
\hline Expiration & 0.990 & $0.95^{\star}$ & $\begin{array}{l}0.89- \\
0.98\end{array}$ & 0.732 & $0.97 *$ & $\begin{array}{l}0.93- \\
0.99\end{array}$ & 0.975 & $0.99 *$ & $\begin{array}{l}0.97- \\
0.99\end{array}$ \\
\hline Inspiration & 0.990 & $0.95^{\star}$ & $\begin{array}{l}0.89- \\
0.98\end{array}$ & 0.506 & $0.84^{*}$ & $\begin{array}{l}0.69- \\
0.93\end{array}$ & 0.975 & $0.99 *$ & $\begin{array}{l}0.97- \\
0.99\end{array}$ \\
\hline \multicolumn{10}{|c|}{ Abdominal area } \\
\hline Expiration & 0.998 & $0.98^{*}$ & $\begin{array}{l}0.95- \\
0.99\end{array}$ & 0.963 & $0.94 *$ & $\begin{array}{l}0.87- \\
0.97\end{array}$ & 0.987 & $0.99 *$ & $\begin{array}{l}0.98- \\
0.99\end{array}$ \\
\hline Inspiration & 0.998 & $0.98^{\star}$ & $\begin{array}{l}0.95- \\
0.99\end{array}$ & 0.933 & $0.98 *$ & $\begin{array}{l}0.97- \\
0.99\end{array}$ & 0.986 & $0.99 *$ & $\begin{array}{l}0.98- \\
0.99\end{array}$ \\
\hline
\end{tabular}


Table 3

Correlation between manual and automatic methods for measuring respiratory rate.

\begin{tabular}{|llll|}
\hline Repetition & $\begin{array}{l}\text { Visual } \\
\text { Mean (SEM) }\end{array}$ & $\begin{array}{l}\text { Matlab } \\
\text { Mean (SEM) }\end{array}$ & R ( $p$-value) \\
\hline $\mathbf{1}(n=18)$ & $55.61(3.48)$ & $56.83(3.18)$ & $0.951(p<0.001)$ \\
\hline $\mathbf{2}(n=18)$ & $55.44(3.59)$ & $56.83(3.21)$ & $0.964(p<0.001)$ \\
\hline $\mathbf{3}(n=18)$ & $55.33(3.58)$ & $57.00(3.25)$ & $0.964(p<0.001)$ \\
\hline All $(n=54)$ & $55.46(2.01)$ & $56.89(1.82)$ & $0.963(p<0.001)$ \\
\hline SEM: standard error of measurement. R: Pearson's correlation coefficient. \\
\hline
\end{tabular}

Table 1.

Table 2.

Table 3.

\section{Discussion}

The study aimed to verify the inter- and intra-examiner reliability of an interactive and personalized $M A T L A B{ }^{\circledR}$ application for the bio-photogrammetric analysis of thoracoabdominal mobility in NB. As result, the model proposed in the present study exhibited excellent inter- and intra-examiner reliability (ICC 0.84-0.99 and ICC 0.81-0.96, respectively), which is essential to confirm instrument validity [21]. In addition, the study also proposed to compare the results of three evaluators and assess the validation of automatic RR measurement in relation to its manual counterpart, showing excellent correlation between manual and automatic models for measuring RR $(r>0.95, p<0.001)$.

Bio-photogrammetric models have been tested in a number of studies [22-24], demonstrating good to excellent reliability levels in body kinematics evaluation, particularly postural analysis, as in the study by Paes et al. (2017) [22],who used Postural Assessment Software (SAPO) to analyze anteriorization and head inclination angles in the anterior and lateral views of the sitting and standing positions. Reliable results can be obtained when the evaluation is carried out by different examiners or by the same examiner on different days. Despite differing from our investigation in terms of the objectives and populations studied, these findings also demonstrate the importance and reliability of alternative biophotogrammetric models for the analysis of body kinematics.

Sarro et al. (2018) [25] set out to investigate the intra and inter-rater reliability and minimal detectable change (MDC) of thoracoabdominal mobility measures using photogrammetry in young adults. In this study, 17 healthy participants were evaluated based on photographs taken during apnea at maximal inspiration and expiration. This strategy was adopted to calculate the latero-lateral and anteroposterior 
diameters of the chest (at the axillary and xiphoid level) and abdomen for analysis using Postural Evaluation Software (SAPO, version 0.68, São Paulo, SP, Brazil). The experienced examiner obtained good reliability (mean intraclass correlation coefficient (ICC): 0.98; mean MDC: 0.3) and inter-observer agreement (mean ICC: 0.97; mean MDC: 0.35) for all measures [25]. Despite being obtained using a different population from ours, these findings corroborate those of the present study, demonstrating excellent inter and intra-examiner reliability in the investigation of thoracoabdominal kinematic measurements using photogrammetry.

From this perspective, bio-photogrammetry has also been applied to evaluate respiratory function by analyzing thoracoabdominal kinematics and synchrony $[8,17,18]$. However, it is important to underscore that the vast majority of current studies were carried out in adolescents or adults, as in the study by Sarro et al. (2018) [25]. As such, this analytical resource should be used to evaluate different age groups, particularly in neonatology, as demonstrated in our study.

Ripka et al. (2014) [18] compared bio-photogrammetry with spirometry in healthy adolescents to test a model capable of predicting lung volumes and capacities and found a high correlation with the spirometric measurements forced vital capacity (0.812), forced expiratory volume in one second (FEV10.708), and peak expiratory flow (PEF - 0.762), showing the importance of including thoracoabdominal mobility variation in predictive equations for total lung capacity [18]. Thus, the findings of the present study justify the use of this assessment method, previously applied in other populations, given its reliability in evaluating the neonatal thoracoabdominal complex, as demonstrated here.

In a study by Caruso et al. (2020) [26] that investigated intra-examiner reliability using photogrammetry in young adult asthmatic patients and healthy controls, the results show moderate reliability for axillary, xiphoid and umbilical mobility (mean ICC of $0.68,0.55$ and 0.73 , respectively) in the asthmatic group, while controls exhibited moderate reliability for axillary mobility (average of 0.68 ) and good reliability for xiphoid and umbilical mobility (average of 0.81 and 0.70 respectively). These findings demonstrate that photogrammetric analysis of thoracoabdominal kinematics is a reliable method and can be included in clinical practice, corroborating our study.

In the present study, image processing using a custom-made MATLAB® routine enabled easy, automatic and fast analysis. Guerra et al. (2017) [7] also conducted thoracoabdominal assessment in NB, applying bio-photogrammetry with AutoCAD $®$ software, reporting difficulties with the instrument because it requires frame-by-frame analysis, prolonging evaluation of each subject [7]. Moreover, the total number of frames analyzed by AutoCAD $®$ is much lower than that achieved by MATLAB $®$ [20], and may produce less reliable results. Oliveira et al. (2016) [20] found that the latter program was superior [20], since it was considered effective in differentiating changes in the delimitation of the thoracoabdominal region. They considered it a useful tool in assessing patients who cannot voluntarily control RR and the synergy of muscle activity during breathing. In addition, the authors underscored that although AutoCAD $₫$ is an effective method, it is time consuming, since each frame takes 10 to 25 minutes to process. 
Bio-photogrammetry analysis in the hospital environment using the MATLAB® App to investigate the kinematics of breathing in NB allows the examiner to infer aspects related to thoracic and abdominal kinematics in a practical and reproducible way. This could contribute to bedside clinical analysis of different health conditions, using the compartmental area for thoracoabdominal kinematics.

In addition to MATLAB's automation and speed, the software offers several pre-applied functions, as well as the freedom to create other routines [27]. This enables extrapolation to other analyses and populations, suggesting further studies. Bio-photogrammetry analysis through the proposed MATLAB ${ }^{\circledR}$ App is a noninvasive resource, with rapid data processing and flexibility in terms of where it can be applied.

Studies using noninvasive lung function tests, which can be easily performed in non-sedated infants at bedside are of particular interest [28]. Some authors have pointed out the variability of breathing as an important functional marker for early investigation of childhood respiratory morbidity [28-30]. The excellent reliability of the present algorithm allows a range of possibilities, since it monitors the respiration cycle breath by breath. On the other hand, MATLAB® is more costly than other processors, such as the conventional $\mathrm{C}$ or Fortran compiler, but this is offset by its advantages [31]. Another limitation is that some of the adhesive markers became detached during filming, precluding the use of these videos. Additionally, the need to keep the baby in a specific position and the possible issue of marker occlusion common to all optical methods are also limitations.

\section{Conclusions}

In summary, bio-photogrammetric assessment of TAM-NB using the proposed MATLAB $®$ App exhibited excellent intra- and inter-examiner reliability, as well as excellent reliability for all areas between assessments 1, 2 and 3 (ICC 0.81-0.99) and a good correlation between manual and automatic models for measuring RR. As such, it can serve as an objective and practical bedside tool for thoracoabdominal mobility assessment in different clinical situations involving neonatal care.

\section{Methods}

This is a cross-sectional study conducted in a maternity school, with 27 healthy NB of both sexes (gestational age between 37 and 41 weeks and up to 72 hours of life) who were not crying during assessment. These neonatal data, as well as the type of delivery, were collected from medical records. Based on the results of Guerra et al. (2017) [7], we used G* Power software version 3.1.9.4 to calculate the sample size, with $80 \%$ power, a $5 \%$ significance level and $5 \%$ effect size, resulting in an estimated sample of 21 NB. However, considering possible sample losses, we increased the sample size to 27 . The aims of the present study and handling procedures necessary for filming were explained to the NB's parents or legal guardians. Those who agreed to participate provided written informed consent. The research was approved by the institutional Research Ethics Committee (number 2.116.308). 
The subjects' RR was determined by measuring the baby's chest excursions for one minute [32].

\section{Video acquisition and analysis procedures}

For video collection, a support bench was set up using two sheets of black rubber. To maximize exposure of the thoracoabdominal region, each subject was placed on the bench in the supine position with shoulders flexed, abducted and externally rotated, and hips flexed at approximately $110^{\circ}$. Red adhesive markers were attached to specific anatomical sites (Fig. 1).

Figure 1.

Each baby was filmed only once for 60 seconds, using a video camera (Sony Cyber-shot® DSC-H20 10.1 $\mathrm{MP}$, at $30 \mathrm{~Hz}$ ) placed $50 \mathrm{~cm}$ from the infant on a 1-meter-high tripod (6)(Gomes et al., 2018). The final layout of the videos, characterized as the exhibition area for TAM analysis, was previously described by Guerra et al. (2017) [7] and Gomes et al. (2018) [6]. The videos eligible for analysis contained 60 seconds of continuous recording and the newborn showed no signs of irritability or crying. Additionally, we did not include NB that had been fed less than 30 minutes before the evaluation, those with congenital malformation, genetic syndrome or respiratory problems, or babies who were crying during assessment. Aspects such as blurry images or the absence of adhesive markers during recording also resulted in exclusion from analysis.

Figure 2.

\section{Kinematic analysis using MATLAB®}

A customized application was developed based on the graphical user interface (GUI), using a MATLAB® (R2018b, The MathWorks, Inc. USA) routine to analyze the TAM-NB (MATLAB® App). The examiners identified the base reference line on the NB's back in the first frame of the video (Fig. 1). Next, the markers were automatically identified and the total thoracoabdominal area divided into two compartments to determine the shape and count the number of pixels between the shape and base reference line. The $M A T L A B \circledast$ App then generated the average and standard deviation of the respiratory rate (breaths per minute), largest and smallest thoracic and abdominal area (end-inspiratory and end-expiratory values) within a recording, and computed the minimum and maximum values of the total areas. Thus, both thoracic and abdominal area time series were computed from 1800 photograms, which were plotted on individual graphs to visualize their variation in each breathing cycle for one minute (Fig. 2).

\section{Data reliability analysis}

Inter- and intra-examiner analyses were conducted to assess the reliability of the method [17]. Interexaminer reliability was carried out with three examiners using different computers. For intra-examiner reliability, the videos were analyzed by the examiners on three different occasions, seven days apart [21, 22]. 


\section{Statistical Analysis}

Statistical analysis was performed using frequency distribution and measures of central tendency and dispersion of the NB's demographic and clinical data. The normality of all numerical variables was determined using the Shapiro-Wilk test, and one-way ANOVA was applied to assess variances in the values obtained by the three examiners.

The intraclass correlation coefficient (ICC) was used to determine inter- and intra-examiner reliability. A $95 \%$ confidence interval and significance level of $a=0.05$ were adopted for all the analyses. Reliability was considered excellent for values between 1.0 and 0.81 , very good for 0.80 to 0.61 , good between 0.60 and 0.41 , fair for 0.40 to 0.21 , and poor between 0.20 and 0.00 [24]. Additionally, Pearson's correlation was applied between the RR values obtained through the automatic (MATLAB ${ }^{8}$ ) and manual Apps (visual exam). Statistical analyses were performed using Statistical Package for the Social Sciences (SPSS ${ }^{\circledR}$ ) version 20 (IBM Corp, Armonk, USA).

\section{Abbreviations}

TAM

Thoracoabdominal mobility; NB:Newborns; OEP:Optoelectronic plethysmography; IRP:Inductive respiratory plethysmography; EIT:Electrical impedance tomography; RR:Respiratory rate; ICC:Intraclass correlation coefficient; SPSS:Statistical Package for the Social Sciences; SAPO:Postural Assessment Software; MDC:Minimal detectable change; FEV1:Forced expiratory volume in one second; PEF:Peak expiratory flow; ANOVA:Analysis of variance.

\section{Declarations}

\section{Ethics approval and consent to participate}

The study protocol was approved by local ethical committees (Committee of the Federal University of Rio Grande do Norte -UFRN), number: 2.116.308, CAAE: 36086614.2.0000.5568.

\section{Consent for publication}

Not applicable.

\section{Availability of data and materials}

The dataset used and analyzed during the current study is available from the corresponding author on reasonable request.

\section{Competing interests}


The authors declare that they have no competing interests.

\section{Funding}

This work was supported in part by Coordination for the Improvement of Higher Education Personnel, Grant/Award Number: Code 001

\section{Authors' contributions}

SAP and AGFA were responsible for study ideation and design of the work; IGA was responsible for statistical analysis; NSOH wrote the initial version of the paper; DCG and FAM reviewed and contributed to the writing of the final version of the paper. AGFA and NSOH participated in the collection of data. All the authors read and approved the final version of the manuscript.

\section{Acknowledgements}

The authors thank: 1) all participants and their legal guardians for taking part in this study, 2) the Ana Bezerra University Hospital for authorizing the present study, 3) the Coordenação de Aperfeiçoamento de Pessoal de Nivel Superior (CAPES) for funding, and 4) the Graduate School of the Federal University of Rio Grande do Norte.

\section{References}

1. Beydon N, Davis SD, Lombardi E, Allen JL, Arets HGM, Aurora P, et al. An Official American Thoracic Society/European Respiratory Society Statement: Pulmonary function testing in preschool children. Am J Respir Crit Care Med. 2007;175(12):1304-45.

2. Lanza F, de C, de Camargo AA, Archija LRF, Selman JPR, Malaguti C, Dal Corso S. Chest wall mobility is related to respiratory muscle strength and lung volumes in healthy subjects. Respir Care. 2013;58(12):2107-12.

3. Peterson-Carmichael S, Seddon PC, Cheifetz IM, Frerichs I, Hall GL, Hammer J, et al. An official American thoracic society/european respiratory society workshop report: Evaluation of respiratory mechanics and function in the pediatric and neonatal intensive care units. Ann Am Thorac Soc. 2016;13(2):1-11.

4. Shaffer TH, Alapati D, Greenspan JS, Wolfson MR. Neonatal non-invasive respiratory support: Physiological implications. Pediatr Pulmonol. 2012;47(9):837-47.

5. Chien JY, Ruan SY, Huang YCT, Yu CJ, Yang PC. Asynchronous thoraco-abdominal motion contributes to decreased 6-minute walk test in patients with COPD. Respir Care. 2013;58(2):320-6. 
6. Gomes VLS, de Farias PHS, Nagem DAP, Gomes DC, Silva GF, de A, Moran. CA, et al. Impact of type of delivery on thoracoabdominal mobility of newborns. J Hum Growth Dev. 2018;28(2):148-53.

7. Guerra JI, de A, Nagem, Moran DAP, Gomes CA, Carvalho VLS, de Pereira JMC. SA.

Thoracoabdominal mobility evaluation by photogrammetry in newborns after expiratory flow increase technique. Fisioter em Mov. 2017;30(4):789-95.

8. Liu F, Kawakami M, Tamura K, Taki Y, Shimizu K, Otsuka T, et al. Feasibility of a respiratory movement evaluation tool to quantify thoracoabdominal movement for neuromuscular diseases. Respir Care. 2017;62(4):423-31.

9. Reinaux CMA, Aliverti A, da Silva LGM, da Silva RJ, Gonçalves JN, Noronha JB, et al. Tidal volume measurements in infants: Opto-electronic plethysmography versus pneumotachograph. Pediatr Pulmonol. 2016;51(8):850-7.

10. Dellaca' RL. Measurement of total and compartmental lung volume changes in newborns. J Chem Inf Model. 2010;et A. OEP(1):1-6. 67(.

11. Tana M, Polglase GR, Cota F, Tirone C, Aurilia C, Lio A, et al. Determination of lung volume and hemodynamic changes during high-frequency ventilation recruitment in preterm neonates with respiratory distress syndrome. Crit Care Med. 2015;43(8):1685-91.

12. Van Der Burg PS, Miedema M, De Jongh FH, Frerichs I, Van Kaam AH. Cross-sectional changes in lung volume measured by electrical impedance tomography are representative for the whole lung in ventilated preterm infants. Crit Care Med. 2014;42(6):1524-30.

13. Parreira VF, Vieira DSR, Myrrha MAC, Pessoa IMBS, Lage SM, Britto RR. Optoelectronic plethysmography: a review of the literature. Rev Bras Fisioter [Internet]. 2012;16(6):439-53. Available from: http://www.ncbi.nlm.nih.gov/pubmed/23184278.

14. Zhang Z, Zheng J, Wu H, Wang W, Wang B, Liu H. Development of a respiratory inductive plethysmography module supporting multiple sensors for wearable systems. Sensors (Switzerland). 2012;12(10):13167-84.

15. Bachmann MC, Morais C, Bugedo G, Bruhn A, Morales A, Borges JB, et al. Electrical impedance tomography in acute respiratory distress syndrome. Crit Care. 2018;22(1):1-11.

16. Gomes DC, Azevedo IG, de Figueiredo Araújo AG, da Costa Lopes LD, Nagem DAP, Magalhães FA, et al. Thoracoabdominal motion in newborns: Reliability between two interactive computing environments. Pediatr Pulmonol. 2020;55(5):1184-9.

17. Ricieri D, V, Rosário Filho NA. Effectiveness of a photogrammetric model for the analysis of thoracoabdominal respiratory mechanics in the assessment of isovolume maneuvers in children. $J$ Bras Pneumol publicaça\{combining double acute Accent o Of da Soc Bras Pneumol e Tisilogia. 2009;35(2):144-50.

18. Ripka WL, Ulbricht L, Gewehr PM. Application of a photogrammetric kinematic model for prediction of lung volumes in adolescents: A pilot study. Biomed Eng Online [Internet]. 2014;13(1):1-9. Available from: BioMedical Engineering OnLine. 
19. Milanesi JM, Borin G, Corrêa ECR, da Silva AMT, Bortoluzzi DC, Souza JA. Impact of the mouth breathing occurred during childhood in the adult age: Biophotogrammetric postural analysis. Int $\mathrm{J}$ Pediatr Otorhinolaryngol. 2011;75(8):999-1004.

20. De Oliveira HB, Pereira SA, Vale BEC, Nagem DAP. Sistema De Reconhecimento De Imagens Para Avaliação Do Movimento Toracoabdominal Em Recem-Nascidos. Rev Bras Inovação Tecnológica em Saúde - ISSN2236-1103. 2016;1:1-10.

21. Pretty IA, Addy L, Maupomé G. A closer look at diagnosis in clinical dental practice: Part 6. Emerging technologies for detection and diagnosis of noncaries dental problems. J Can Dent Assoc (Tor). 2004;70(9):621-6.

22. Paes JL, Piazza L, Tormen L, Libardoni T, de C, Pasquali, Santos T. GM. Confiabilidade intra e interexaminador da avaliação do alinhamento da cabeça nas posições sentado e em pé. Fisioter e Pesqui. 2017;24(1):29-39.

23. Alves RS, Pereira IC, lunes DH, Rocha CBJ, Botelho S, Carvalho LC. Análise intra e interavaliadores da projeção do centro de massa do corpo obtido por fotogrametria. Fisioter e Pesqui. 2017;24(4):34955.

24. Ferreira EAG, Duarte M, Maldonado EP, Burke TN, Marques AP. Postural assessment software (PAS/SAPO): Validation and reliabiliy. Clinics. 2010;65(7):675-81.

25. 10.1080/09593985.2017.1423525

Sarro KJ, Mombrini CL, Tonole TB. Reliability and minimal detectable change of thoracoabdominal mobility measurements using photogrammetry. Physiother Theory Pract [Internet]. 2018;34(9):7309. Available from: https://doi.org/10.1080/09593985.2017.1423525.

26. Caruso FR, Trimer R, da Luz Goulart C, Ricci PA, Araújo ASG, Carmargo P, et al. Thoracoabdominal mobility evaluation of asthmatic patients in physiotherapy practice: Intra-rater reliability. Physiother Res Int. 2020;25(3).

27. Weir JP. Quantifying test-retest reliability using the intraclass correlation coefficient and the sem. J Strength Cond Res. 2005;1(19):231-40.

28. Frey U, Maksym G, Suki B. Temporal complexity in clinical manifestations of lung disease. J Appl Physiol. 2011;110(6):1723-31.

29. Usemann J, Suter A, Zannin E, Proietti E, Fouzas S, Schulzke S, et al. Variability of Tidal Breathing Parameters in Preterm Infants and Associations with Respiratory Morbidity during Infancy: A Cohort Study. J Pediatr. 2019;205:61-9.e1.

30. Fouzas S, Theodorakopoulos I, Delgado-Eckert E, Latzin P, Frey U. Breath-to-breath variability of exhaled CO2 as a marker of lung dysmaturity in infancy. J Appl Physiol. 2017;123(6):1563-70.

31. Chapman SJ. Programação em MATLAB® para engenheiros. Tradução técnica: Flávio Soares Correa da Silva. São Paulo: Pioneira Thomson Learning (2003); 1-20.

32. Jorge J, Villarroel M, Chaichulee S, Green G, McCormick K, Tarassenko L. Assessment of Signal Processing Methods for Measuring the Respiratory Rate in the Neonatal Intensive Care Unit. IEEE J Biomed Heal Informatics. 2019;23(6):2335-46. 


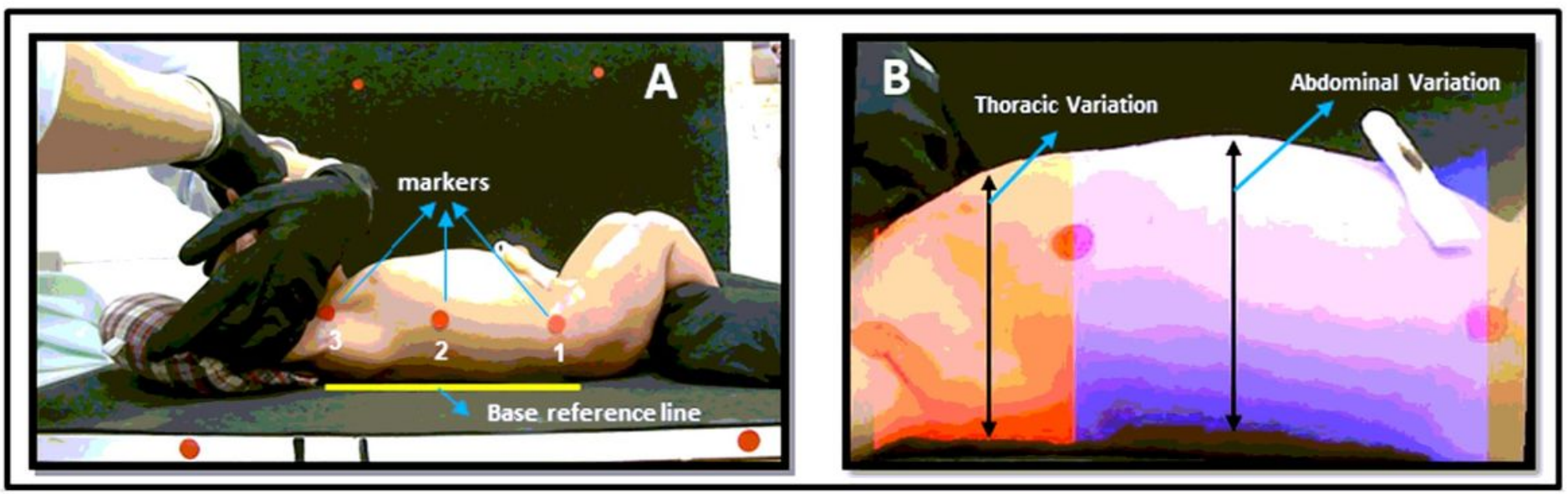

Figure 1

A. Representation of the positioning of the newborn, collection scenario of the examiners and anatomic sites: (1) anterior superior iliac spine; (2) lateral projection of the xiphoid process; and (3) jugular notch of the manubrium of sternum. Figure 1.B. Image of thoracic and abdominal wall delimitation and variation performed by the interactive model during analysis of area variation. The red markers serve as a reference for the program to delineate thoracic and abdominal areas. 


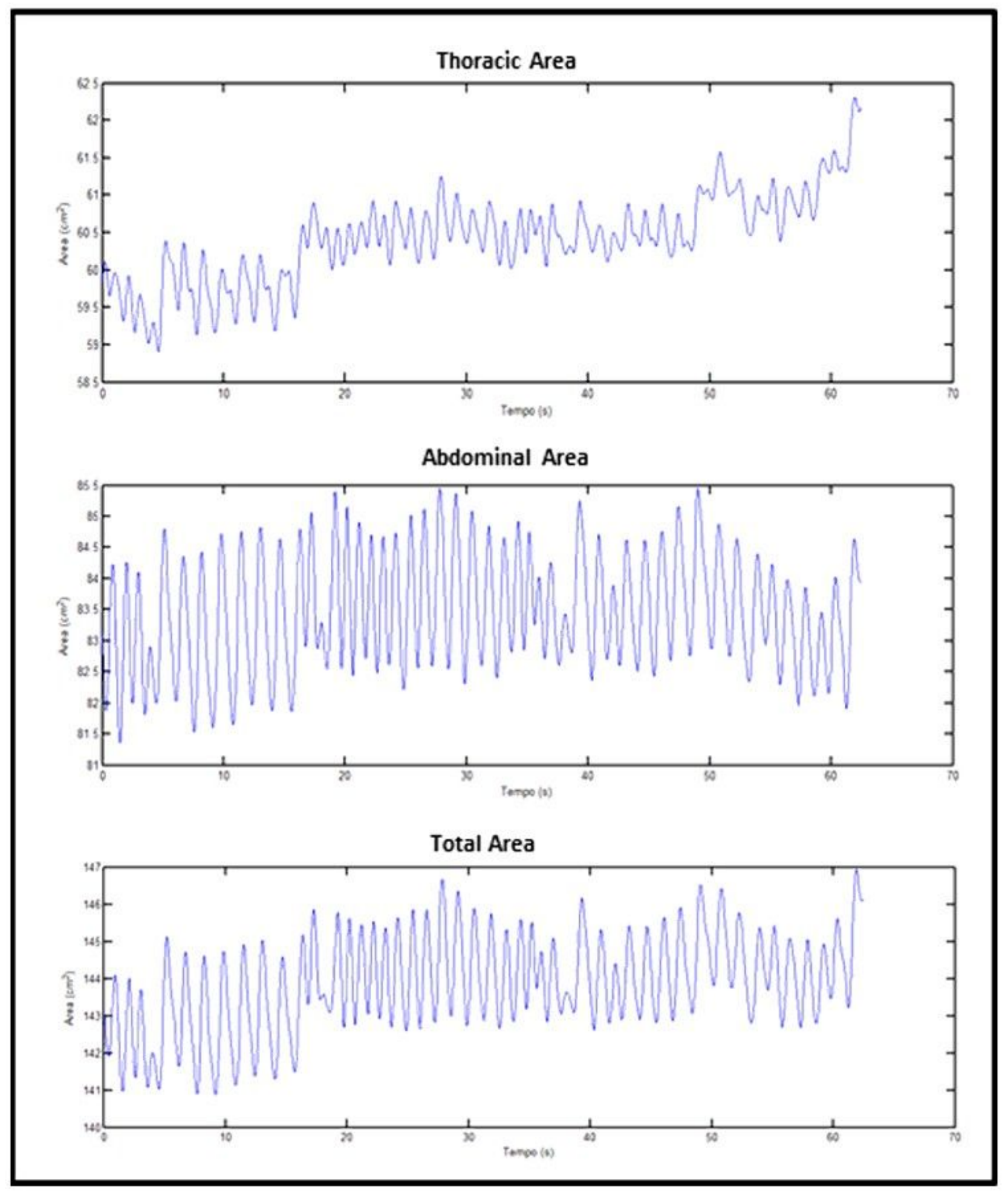

Figure 2

Graphical representation of the variation in thoracic, abdominal and total areas for each respiratory cycle for one minute, obtained at the end of interactive model analysis. 